\title{
Particularities of the sustainable energy technologies and labour market in Russia
}

\author{
Elena Kostromina ${ }^{1}$, Marina Danilina ${ }^{1,2,3,4, *}$, Svetlana Ivanova $^{5}$, Natalia Bespalova $^{6}$, Yulia \\ Golikova $^{7}$, Ivan Kondrashov ${ }^{7}$, and Yury Kosolapov ${ }^{8}$ \\ ${ }^{1}$ Moscow University named after S.Yu. Vitte (MUIV), $2^{\text {nd }}$ Kozhukhovsky proezd, 12, stroyeniye 1, \\ 115432, Moscow, Russia \\ ${ }^{2}$ Research Institute VNII of Labor, Ministry of Labour of Russia, Zemlyanoy Val, 34, 105064 \\ Moscow, Russia \\ ${ }^{3}$ Plekhanov Russian University of Economics (PRUE), Stremyanny per., 36, 117997 Moscow, Russia \\ ${ }^{4}$ Finance University under the Government of the Russian Federation, Leningradsky prosp., 49, \\ 125993 Moscow, Russia \\ ${ }^{5}$ Moscow State Psychologo- Pedagogical University MGPPU (Moscow State University of \\ Psychology and Education, MSUPE), ul. Sretenka, 29, Moscow, Russia \\ ${ }^{6}$ Altai State Institute of the culture, Socialist pr., 68, Barnaul, Russia \\ ${ }^{7}$ Gzel'skii State University, posiolok Elektroizoliator, 67, Russia \\ ${ }^{8}$ Juridical Institute RUT (MIIT), 127055, Obraztsova str., 9, building 4, Moscow, Russia
}

\begin{abstract}
The energy sector is now experiencing a renaissance thanks to new opportunities offered by innovative technologies that are filling the market, for example in the field of storage and management of electrical energy. For the controlled development of distributed generation, maintaining the stability of the energy system while maintaining the price advantages of small generation, the speed of commissioning new power capacities and the scalability of the solutions used, a new subject of relations in the electricity market is proposed - an active energy complex. This is an energy system that is electrically connected within the general boundaries of the balance sheet membership, which includes energy receiving, generating, accumulating (if any), electric grid energy equipment and a control system for this energy system as a single complex in order to meet energy needs. There is a contradiction between the development of the labour market and the achievement of environmental well-being. On one hand, environmental pollution, depletion of natural capital has a negative impact on the state of the labour market, employment of the population, and on the other hand - activities to improve the environment, eliminate the accumulated environmental damage, the development of a market for environmental works, goods and services promote the expansion of employment, not only green, but general employment.
\end{abstract}

${ }^{*}$ Corresponding author: marinadanilina@yandex.ru 


\section{Introduction}

Sustainable energy is an energy supply that can meet current demand without jeopardizing the energy supply for future generations and without harming the environment. It covers the production, distribution and use of energy. In the field of energy production, it relies on renewable energy sources and, among other things, on improving energy efficiency. The transition from a fossil nuclear to a sustainable energy supply is called an energy transition. The energy sector is now experiencing a renaissance thanks to new opportunities offered by innovative technologies that are filling the market, for example in the field of storage and management of electrical energy.

Innovations have significant impact on the transformation of various industries around the world. And energy is no exception to this rule. Increasingly, the small devices that powered our phones or computers just a few years ago are now capable of charging cars and even buildings. And it's not just the size-to-power ratio that has changed - energy sources have also changed significantly. According to UBS (CNBC), energy storage costs will decline $66 \%$ and $80 \%$ over the next decade, while the global energy market will grow to $\$ 426$ billion.

Today, technological advances are increasingly reshaping the landscape of the energy industry and enabling the generation of energy through portable devices similar to computers and telephones, but powerful enough to provide electricity to homes. In the near future and due to potential natural disasters, I expect renewables to replace non-renewable energy sources and eliminate the current dependence of consumers on fossil fuels $[1,2]$.

Of course, a full transition to sustainable energy is still far in the future. Today, the world is still largely dependent on traditional energy sources and may perceive new energy solutions as temporary and passing. It is worth remembering, however, that traditional methods are expensive or non-functional. With innovation entering the market and revolutionizing the energy space, companies that are pursuing innovation still need to think about how ready consumers are for such a big change and how likely they are to embrace it from the start.

\section{Materials and methods}

On the basis of the content analysis method the authors analyse the application of the sustainable energy technologies. For the first time in Russian practice, the decree of the Government of Russia approved the procedure for creating industrial microgrids - active energy complexes (AEC). AEC is a new effective integrated solution for power supply to commercial and industrial consumers of electricity through the use of distributed generation technologies, energy storage systems, electrical load control systems, modern digital solutions to optimize power supply management. The technology of active energy complexes also includes the possibility of implementing local peer-to-peer electricity trading.

According to model estimates and international experience in the use of industrial microgrids, AEC will reduce the total costs of consumers for power supply by $15-20 \%$, especially if these consumers, due to the growth of their consumption, begin to experience a power shortage from the network. For the energy system, active energy complexes will be useful in that they will reduce the need for investments in generation and network construction, as well as attract direct private investment from consumers themselves to the energy sector [3, 4].

AEC will be industrial microgrids created by commercial and industrial consumers and connected to the power grids of the UES according to a special procedure based on the use of a controlled intelligent connection (MIS). The functionality of the UIS consists in 
controlling the amount of power flow between the Unified Energy System and active energy complexes strictly within the limits of the required value declared by the AEC. Due to its own energy sources, this amount of overflow can be significantly lower than the power consumed by the AEC subjects.

Until 2023, active energy complexes will be created as a pilot project. Piloting will make it possible, in practice, to work out the best solutions for the legal regulation of the activities of microgrids, the interaction of entities within them, the relationship of such microgrids with the UES and stakeholders of large energy. The best solutions will form the basis of a target permanent regulatory model for the use of active energy complexes in Russia [3, 4].

In recent years, Russia has seen an increase in the share of distributed generation owned by industrial consumers. The prerequisites for the introduction of their own generating facilities by such consumers are an increase in the availability of modern technologies for efficient low-maintenance distributed generation, the continuously growing cost of electricity, as well as legislative stimulation of the utilization of associated petroleum gas and the need of industrial enterprises for efficient sources of heat or cold.

The departure of solvent consumers from the UES of Russia becomes uncontrollable, which discriminates against consumers remaining in the power system, worsens the quality of their power supply, the economic condition of generating and grid companies, and also negatively affects the reliability and safety of the power system as a whole.

\section{Results}

For the controlled development of distributed generation, maintaining the stability of the energy system while maintaining the price advantages of small generation, the speed of commissioning new power capacities and the scalability of the solutions used, a new subject of relations in the electricity market is proposed - an active energy complex.

This is an energy system that is electrically connected within the general boundaries of the balance sheet membership, which includes energy receiving, generating, accumulating (if any), electric grid energy equipment and a control system for this energy system as a single complex in order to meet energy needs.

For the controlled development of distributed generation, maintaining the stability of the energy system while maintaining the price advantages of small generation, the speed of commissioning new power capacities and the scalability of the solutions used, a new subject of relations in the electricity market is proposed - an active energy complex.

This is an energy system that is electrically connected within the general boundaries of the balance sheet membership, which includes energy receiving, generating, accumulating (if any), electric grid energy equipment and a control system for this energy system as a single complex in order to meet energy needs. The draft resolution forms the mandatory requirements for the creation of the AEC. Compliance with quantitative and other characteristics is required: the total installed generating capacity must be less than $25 \mathrm{MW}$, within the boundaries of the AEC there is no population and categories of consumers equated to it, there are no power grid facilities used to provide services for the transmission of electrical energy, there is no flow of electric energy through the AEC (power).

Potential AEC participants must take technical measures to change the parameters of the technological connection and equip the connection point with an automated control system.

Based on the results of the experiment and its results, it is planned to formulate proposals on the feasibility of disseminating the experience of creating and operating the AEC in order to make appropriate changes to the regulatory legal framework.

A new trend in the modern labour market is the development of policy promoting employment based on the principles of a green economy. From a personal sign of such a 
policy is the formation of an environmentally oriented to a healthy labour market by creating green jobs that promote reducing the negative impact on the environment and improving the ecological situation.

There is a contradiction between the development of the labour market and the achievement of environmental well-being. On one hand, environmental pollution, depletion of natural capital has a negative impact on the state of the labour market, employment of the population, and on the other hand - activities to improve the environment, eliminate the accumulated environmental damage, the development of a market for environmental works, goods and services promote the expansion of employment, not only green, but general employment. For the development of the green employment in Russia it is required the development and implementation of a detailed plan actions, including the identification of indicators characterizing such development, and division of priority economic activities to create green barrel seats.

\section{Discussions}

Energy technologies are used in power engineering (fuel and energy complex) and in power engineering. Since the second half of the 20th century, under the conditions of the scientific and technological revolution, the needs of human society for a large amount of energy, mainly electrical, grew especially rapidly. Qualitative changes are also taking place as a result of the transition to the electrification of industrial production, from the transition of a high-quality monostructure of a fuel pipeline to the widespread use of oil, natural gas, and nuclear fuel; creation of unique parameters and length of transmission facilities for energy resources and electricity, common for the countries of the energy system.

Scientific and technological progress in the energy sector is expressed in the development of new methods of energy production and conversion, the enlargement of energy-producing equipment, the improvement of means for the extraction of energy resources, the creation of new technologies. The interchangeability of various types of energy, installations that produce it, and individual energy resources is developing. The concentration of production and means of transmission of converted types of energy (primarily electricity), energy resources, and the centralization of their distribution are growing.

The intensive development of energy technologies is closely related to the scientific and technological revolution. The largest inventions were made in power engineering, which ensured colossal technological progress of the XX century. A new type of energy electricity - and a new type of universal heat engine - a steam turbine - these are the main achievements of the power industry, which had a revolutionizing effect on the entire technology of this era.

In the $70 \mathrm{~s}-80$ s of the XIX century. major scientific generalizations were made in the field of the study of electricity and magnetism. Experimental data accumulated in the study of electricity and magnetism in the first half of the 19th century. (experiments of Faraday and others), provided material for the creation of Maxwell's electromagnetic theory, which became the basis for the development of electrical engineering in the late 19th - early 20th centuries. At this time, an intensive development of theoretical issues of electrical engineering began, associated with the practical use of electricity in various areas of production $[5,6]$.

First of all, engineering thought turned to the issue of sources of electricity - generators, since without a rational source of electric current capable of generating currents of the required power and frequency, it was impossible to introduce electricity into industrial production. The most significant achievement was the invention by engineers Gramm, 
Gefner-Alteneck, Fontaine and others of an electromagnetic generator with self-excitation and a ring armature.

The problem of electric power transmission over long distances was developed mainly in the 80 s of the XIX century. In the course of numerous experiments, the Russian scientist Lachinov and the Frenchman Despres, by increasing the voltage in the transmission line, outlined the correct way to solve this problem. At the end of the XIX century. the problem of long-distance transmission of electricity has been largely resolved. The technical means that made it possible to solve it was the use of alternating current, first single-phase, then two-phase, and finally three-phase, the transmission of which turned out to be the most profitable and convenient. The three-phase current system was proposed by the Russian engineer M.O. Dolivo-Dobrovolsky [5, 6].

In the 90 s of the XIX century. extensive construction of power plants and long-distance power lines was launched. The development of power plants required the creation of a more powerful and rational heat engine capable of servicing them. The steam engine was unsuitable for this purpose. And as a result of research by heating engineers in Europe and the USA, a qualitatively new type of heat engine appeared - a steam turbine $[5,6]$.

Solving the problem of long-distance transmission of electricity freed the industry from the constraining local energy conditions. Electrical energy from the beginning of the XX century. firmly entered industrial production, first in the form of a group, and then an individual electric drive, which carried out the reconstruction of the entire power economy of the machine industry at the beginning of the 20th century.

\section{Conclusion}

To conclude, the world is not on the path to a sustainable energy future. Historically, the highest levels of oil prices have increased concerns about long-term balances of supply and demand. Over the past decade, CO2 emissions have increased by over $20 \%$. In fact, if future developments are consistent with current trends, as shown in the baseline scenario of the World Energy Outlook 2005, CO2 emissions and oil demand will continue to grow rapidly over the next 25 years. This should take into account the gains in energy efficiency and technical progress that can be expected as a result of the current policy in this area. An extension of this projection beyond 2030 suggests that these worrisome trends are likely to intensify.

In the baseline scenario developed in the framework of this study, by 2050, CO2 emissions will be almost 2.5 times higher than the current level. The increased demand for transport will continue to put pressure on oil supplies. The carbon intensity of the global economy will increase as a result of the increasing involvement of coal in power generation, especially in the rapidly growing economies of developing countries with their own coal reserves, and the increased use of coal in the production of liquid transport fuels.

However, this alarming outlook is subject to change. The Accelerated Technology scenarios (ACT) underlying this book demonstrate that by leveraging existing technologies, or those under development, the world can move towards a much more sustainable energy model. These scenarios show how energy-related $\mathrm{CO} 2$ emissions can be maintained at their current levels by 2050 and how the growth in oil demand can be mitigated. They also show that by 2050 , energy efficiency measures could lead to a one-third decrease in electricity demand compared to the Baseline. Savings in liquid fuels could reach more than half of today's global oil consumption, offsetting about $56 \%$ of the growth in oil demand in the Baseline Scenario [5, 6].

Significant changes noted in the Accelerated Technology Evolution (ACT) scenarios are as follows:

- significant increases in energy efficiency in transport, industry and construction; 
- a significant decrease in electricity production from fossil fuels due to the fact that electricity generation will increasingly be based on nuclear energy, renewable energy sources, natural gas and coal, taking into account $\mathrm{CO} 2$ capture and storage (Carbon Capture and Storage, CCS);

- the growing use of biofuels in road transport.

Nevertheless, even in the ACT scenarios, fossil fuels will still provide most of the world's energy needs in 2050, while the demand for oil, coal (with the exception of one of the scenarios) and natural gas in 2050 will even will increase from today's level. Consequently, investments in the development of conditioned energy sources will be of decisive importance.

In all five AST scenarios, the demand for energy service provision will increase rapidly, especially in developing countries. These scenarios do not assume that the growth in demand for energy services in both developing and developed countries will be limited. They are more of a demonstration of how this demand can be met in the most efficient way while maintaining low $\mathrm{CO} 2$ emissions. In particular, by increasing the role of research and development (R\&D) and Demonstration and development of programs for the implementation of R\&D results, as well as the expansion of economic initiatives to promote technologies with low carbon emissions.

The envisaged policy framework is the same in all five ACT scenarios. Only estimates of how quickly energy efficiency can improve, how quickly the costs of introducing basic technologies such as $\mathrm{CO} 2$ capture and storage (CCS), renewable energy and nuclear power can be reduced, and how soon these technologies can change. become widely available. The sixth scenario, TECH Plus, illustrates the results of more optimistic assessments of possible progress in the use of technologies based on renewable sources and nuclear energy to generate electricity, as well as biofuels and hydrogen fuels in transport.

In ACT scenarios, the costs of achieving more sustainable energy in the future are not disproportionately large, but they require significant efforts and investment from both the public and private sectors. None of the required technologies, once fully commercialized, are expected to increase costs by more than $\$ 25$ per tonne of unrealized $\mathrm{CO} 2$ emissions in all countries, including developing countries.

Over the next two decades, significant additional intermediate costs can be expected associated with $\mathrm{R} \& \mathrm{D}$ and the demonstration and development of programs for the commercialization of many technologies. Oil import prices will decline as lower demand will reduce pressure on more expensive supply decisions. However, these cost reductions will be little perceptible at the consumer level, as they will largely be balanced by rising costs of promoting lower carbon technologies.

\section{References}

1. Energy Management, A comprehensive guide to controlling energy use, Carbon Trust (2013)

2. D. Rodrik, C. Sabel, Industrial Policy for the Twenty-First Century (2004) http://www.vedegylet.hu/fejkrit/szvggyujt/rodrik_industrial_policy.pdf

3. D.O. Skobelev, Environmental Industrial Policy In Russia: Economic, Resource Efficiency And Environmental Aspects, International Multidisciplinary Scientific GeoConference SGEM 19, 5.3, 291-298 (2019)

4. CEFIC: Facts and Figures of the European Chemical Industry, https://cefic.org/app/uploads/2018/12/Cefic_FactsAnd_Figures_2018_Industrial_BRC HURE_TRADE.pdf 
5. T. Guseva, et al. Integrated Pollution Prevention and Control: Current Practices and Prospects for the Development in Russia, Proceedings of the International Multidisciplinary Scientific GeoConference Surveying Geology and Mining Ecology Management, SGEM 14, 391-398 (2014)

6. T.V. Guseva, K.A. Shchelchkov, A.Yu. Sanzharovsky, Ya.P. Molchanova, Best Available Techniques, Energy Efficiency Enhancement and Carbon Emissions Reduction, International Multidisciplinary Scientific GeoConference SGEM 19, 5.1, 63-70 (2019) 